\title{
Vermilionectomy for a Progressively Actinic Cheilitis: Case Report
}

\section{Mônica Simões Israel, Giulianna Lima Pinheiro, Nathália de Almeida Freire, Sarah Aparecida Antero}

Department of Diagnosis and Surgery, School of Dentistry, State University of Rio de Janeiro, Rio de Janeiro, Brazil

Email: monicasisrael@yahoo.com.br

How to cite this paper: Israel, M.S., Pinheiro, G.L., Freire, N. de A. and Antero, S.A. (2016) Vermilionectomy for a Progressively Actinic Cheilitis: Case Report. Open Access Library Journal, 3: e3103.

http://dx.doi.org/10.4236/oalib.1103103

Received: September 27, 2016

Accepted: October 31, 2016

Published: November 3, 2016

Copyright $\odot 2016$ by authors and Open Access Library Inc.

This work is licensed under the Creative Commons Attribution International License (CC BY 4.0).

http://creativecommons.org/licenses/by/4.0/

\begin{abstract}
Actinic cheilitis (AC) is a potentially malignant disorder of the lip caused by exposure to solar radiation. It is a premalignant condition that affects 40 -year-old males more commonly. Diagnose must be based on the histopathological exam, considering the degrees of dysplasia. Although there is not an established protocol of treatment to AC, whenever there is severe degrees of dysplasia the vermilionectomy is recommended. The aim of this study is to report a case of AC with moderate dysplasia that was initially treated with diclofenac in hyaluronic acid gel, but evolved to an intense dysplasia, and then submitted to vermilionectomy. We concluded that vermilionectomy is the treatment of choice in cases where there is intense dysplasia.
\end{abstract}

\section{Subject Areas}

Pathology

\section{Keywords}

Cheilitis, Lip, Therapeutically Approaches, Vermilionectomy

\section{Introduction}

Actinic cheilitis (AC), also known as cheilitis exfoliativa, solar cheilosis, solar keratosis, and actinic keratosis of the lips is a common, potentially malignant lesion that affects the lower lip vermilion. Its main etiological factor is chronic exposure of the lips to ultraviolet (UV) radiation component of sunlight, especially type B (UVB). Actinic cheilitis is similar to actinic keratosis of the skin in its pathophysiologic and biologic behavior [1].

AC is more common in white men, especially those who experience occupational sun exposure, such as fishermen and agricultural workers. The most common clinical presentation is pale, scaly lips, presenting with a dry area of varied thickness and asso- 
ciated erythema; while at advanced stages, leukoplakia and/or erithroplakia areas appear, potentially along with chronic ulcerations and erosions [2]. Verticalfolds of the lips can become more pronounced, and gray-white discoloration can become apparent [3].

The histopathologic aspects of AC include hyperplasia, acanthosis or atrophy of the epithelium, thickening of the keratin layer, and/or dysplasia, which may range from mild to severe. In connective tissue, basophilic degeneration of collagen fibers, called solar elastosis, is usually detected [4].

It is important to monitor periodically AC patients and perform incisional biopsies in lesions with more severe clinical aspects in order to prevent their malignant transformation. There are many ways to treat AC, including application of 5-fluorouracil, peeling with trichloroacetic acid 50\%, imiquimod 5\%, electrosurgery, photodynamic therapy, $\mathrm{CO}_{2}$ laser, vermilionectomy, cryosurgery, and dermabrasion [3]. In cases involving severe epithelial dysplasia, therapeutic methods include surgical excision (vermilionectomy), cryosurgery and laser surgery [1].

Vermilionectomy is a well-recognized technique and an excellent alternative for treatment of AC since it is easy to perform it and since it provides satisfactory aesthetic results according to several authors [2].

We present a case of AC previously treated with use of diclofenac in hyaluronic acid gel for 16 weeks without positive results that was evolved to intense epithelial dysplasia and then was submitted to vermilionectomy.

\section{Case Report}

A 62-year-old white male, farmer for 30 years, with excessive exposure to the sun, came to the Oral Medicine Clinic of Dentistry College of Rio de Janeiro State University complaining claiming about irritation on the lower lip for a year. He stated that he drinks socially but did not smoke. The clinical exam revealed the presence of bilateral leukoerithroplakic lesions, with ulcerated sites and dryness of the inferior lip vermilion (Figure 1). The main diagnostic hypotheses were actinic cheilitis and oral squamous cell carcinoma. An incisional biopsy was performed on areas where slight accentuations of clinical findings could be detected and confirmed the existence of AC with moderate epithelial dysplasia and solar elastosis, and excluded oral squamous cell carcinoma (Figure 2). We started the treatment using diclofenac in hyaluronic acid gel twice a day, for 16 weeks. After this period of treatment without clinical improvement (Figure 3), a new incisional biopsy was performed and microscopic examination showed epithelial changes with intense dysplasia and solar elastosis (Figure 4). Due to the failure of drug therapy, a therapeutic vermilionectomy was performed. Patient received antibiotic prophylaxis with oral amoxicillin one hour before procedure and dexamethasone for edema control 30 minutes before. He was asked to rinse out with chlorhexidine $0.12 \%$ during one minute. Antisepsis with alcohol 70 was also proceeded in the extra oral labial-cutaneous junction. After topical application of benzocaine $20 \%$, local anesthesia with a solution of lidocaine $2 \%$ and epinephrine 1:100.00 was carried out, start- 


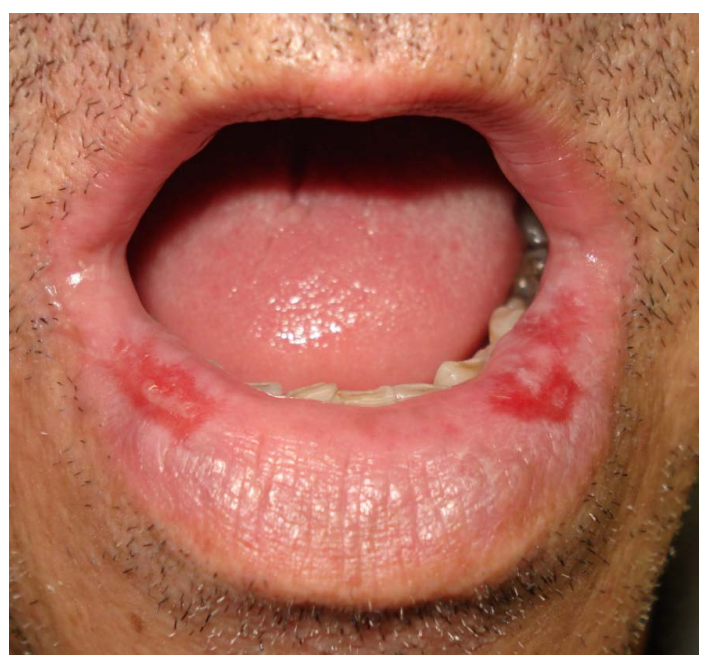

Figure 1. Bilateral leukoerithroplakic lesions, with ulcerated sites and dryness of the inferior lip vermilion.

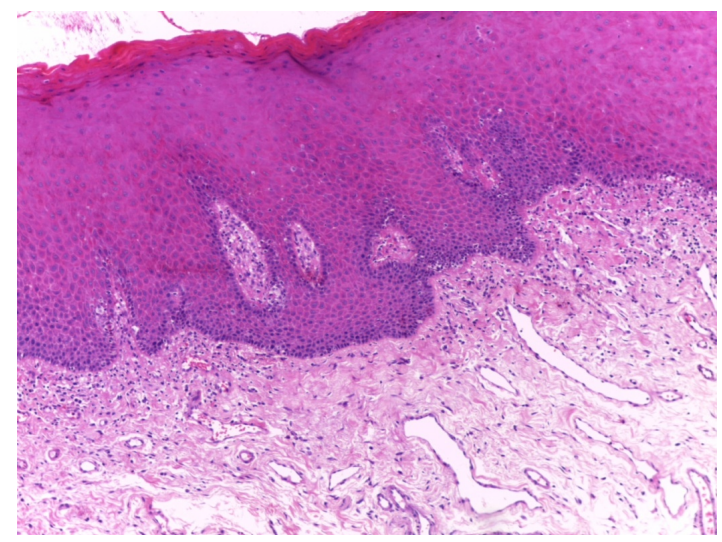

Figure 2. Photomicrograph showing moderate epithelial dysplasia and solar elastosis (HE stainoriginal magnification $10 \times$ ).

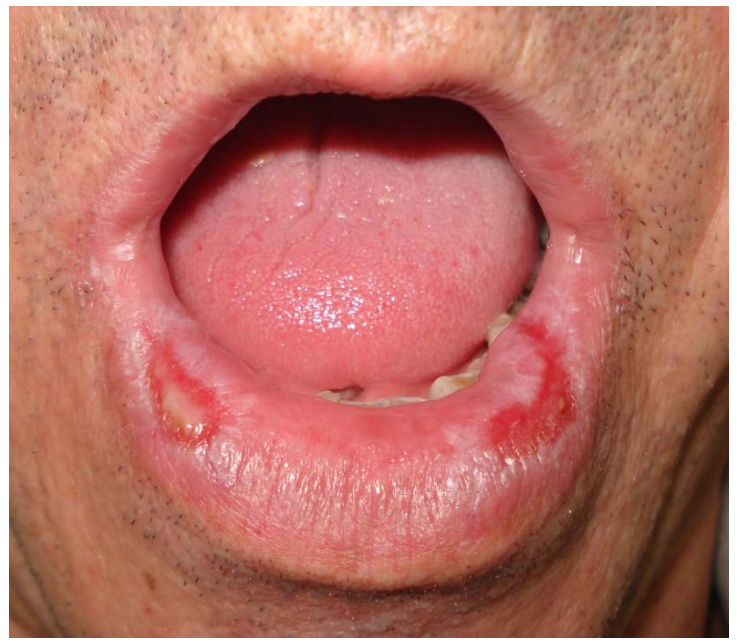

Figure 3. Clinical appearance after 16 weeks of use of diclofenac in hyaluronic acid gel twice a day. 


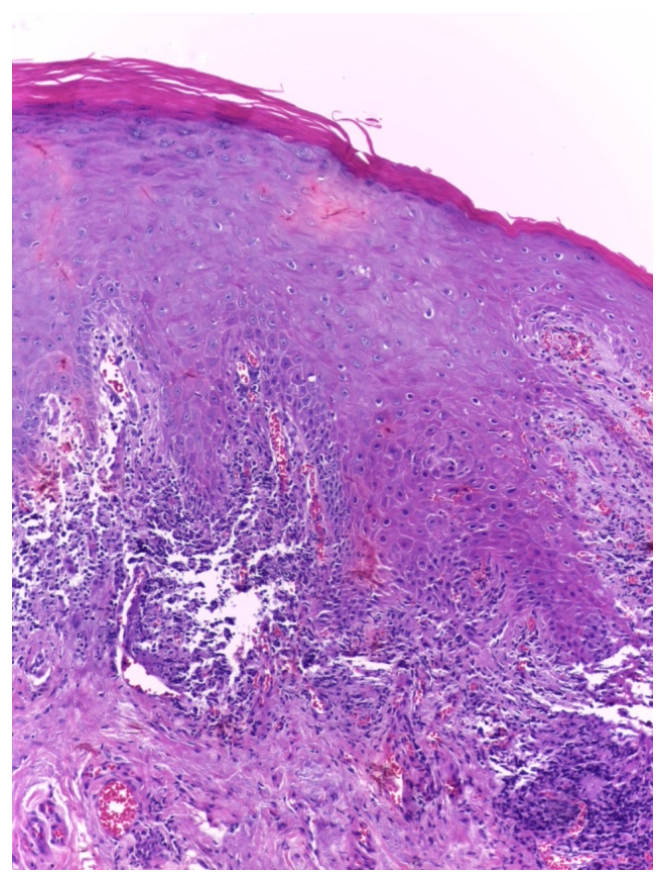

Figure 4. Photomicrograph showing intense epithelial dysplasia (HE stain-original magnification $10 \times)$.

ing with punctures and very slow injections in the extra oral labial-cutaneous junction and then in the intraoral labial mucosa. Care was taken not to deform labial anatomy with excess of solution and/or fast injections. Two incisions were designed to perform vermilionectomy: using a number 15 blade, the first one was positioned exactly in the extra oral labial-cutaneous junction; and using electric scalpel, the second one was positioned in the line that delimits labial mucosa and vermilion lip. The two incisions met each other near the labial commissure bilaterally. A delicate forceps with teeth grabs the right vertex formed by the union of the two incisions while an electric scalpel gently separated a fine slice that includes vermillion and a very small portion of the subcutaneous cellular tissue (Figure 5(a) and Figure 5(b)). Care was taken not to remove portions of muscle. Bleeding control was obtained with slight electric coagulation. Then, the same delicate forceps grabs the labial mucosa and a delicate curved Metzembaun scissors separated the mucosa from de muscle, maintaining 1 centimeter depth in all extension from commissure to commissure. Finally, suturing with nylon was performed to bring together the flap and the cutaneous line, covering the surgical wound. Nylon 3-0 was used in the first points and then nylon 4-0. Routine recommendations for oral surgery were observed, including especially pain and edema control and sun exposure avoidance. After 7 days first points were removed. The applying of petroleum jelly many times a day helped in release of encrustations. After 14 days from surgery, last points were removed. Patient was asked to start using sunblock. The ressected vermilion was formalin-fixe and subjected to histopathological examination that showed areas of intense dysplasia and solar elastosis (Figure 6). The healing was uneventful after a month (Figure 7). 


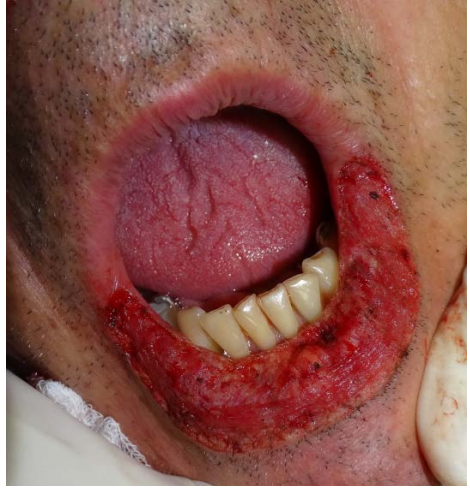

(a)

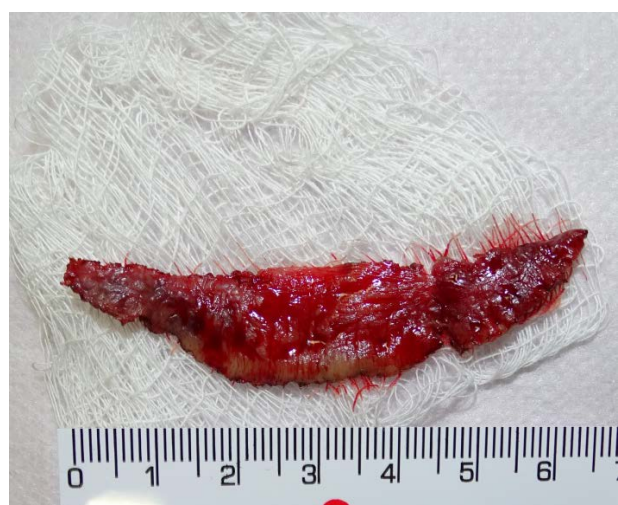

(b)

Figure 5. Vermilionectomy. Fine slice of vermillion of the lower lip removed.

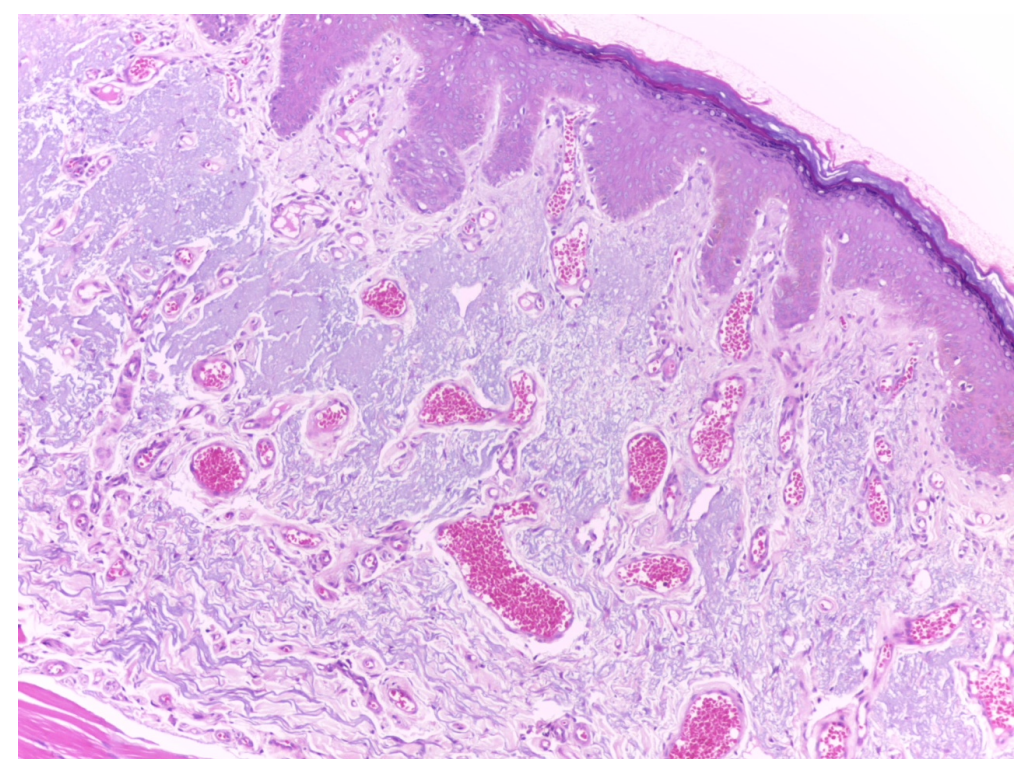

Figure 6. Photomicrograph showing epithelial dysplasia and intense elastosis (HE stain-original magnification $10 \times)$.

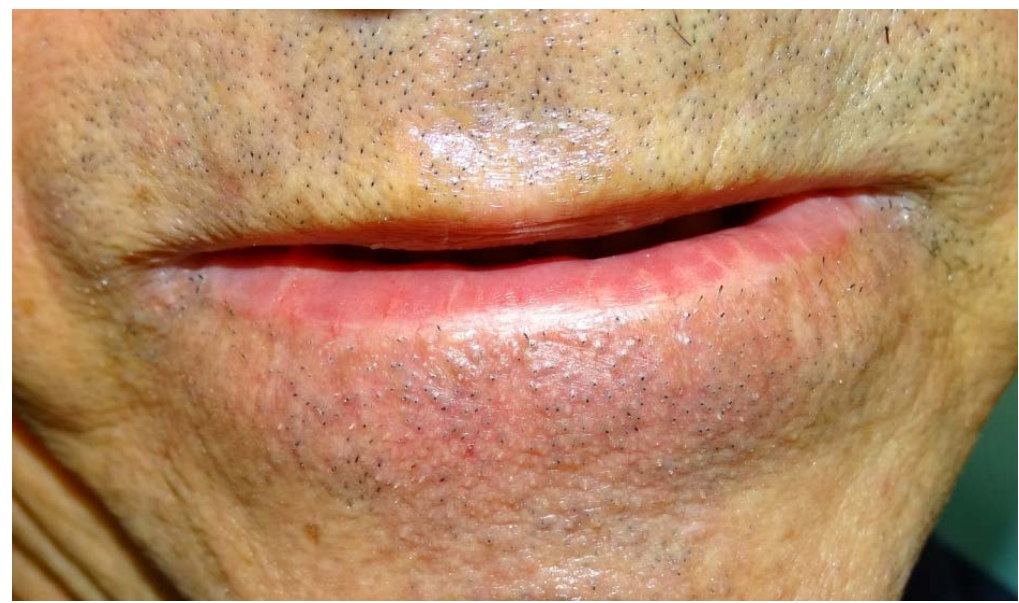

Figure 7. After one month of the vermilionectomy. 


\section{Discussion}

Actinic cheilitis is the most common potentially malignant lip lesion. The frequency of malignant transformation of these lesions ranges from $10 \%$ to $30 \%$. Solar radiation is well established in the literature as the main etiologic factor for the development of AC and its progression to lower lip SCC, for which ultraviolet B (UVB) radiation is mainly responsible [5] [6]. Ultraviolet radiation induces changes in proteins and DNA which initiate and promote dysplastic changes in the epidermis [7]. The most important risk factors for AC are outdoor activity and skin type. Factors such as socioeconomic status, lifestyle risk factors such as smoking and dietary habits, and genetic predisposition may be associated with AC and progression to SCC [4].

Actinic cheilitis is clinically characterized by atrophy of the red part of the lower lip, with loss of elasticity, and keratotic plaques ranging from thin to thick, rough and scaly, overlapping irregular erythematous areas, in addition to ulcers and fissures. A relevant aspect is the loss of a clear separation between the labial semimucosa and the skin [8]. His physical examination revealed keratotic plaques and irregular eirthroplakic areas, including ulcers. However, it was not possible to observe the loss of the limits between the lip vermilion and the skin.

Although there is no AC protocol treatment, some authors have sought alternative treatments, such as Lima et al., who reported the promising use of diclofenac in hyaluronic acid gel, which is a noninvasive treatment with minimal side effects [9]. Diclofenac, a nonsteroidal anti-inflammatory drug, decreases proliferative cell cycle dynamics by inhibiting prostaglandin formation. Diclofenac therapy was reported to have far fewer side effects than 5-FU treatment, as most study participants experienced only painless lips welling [3]. In this case, the diclofenac treatment was not effective, because there is advancement of moderate do intense epithelial dysplasia. Further studies are needed to evaluate diclofenac as a standard treatment option.

Vermilionectomy is an excisional technique for the treatment of lower lip squamous cell carcinoma and actinic cheilitis. The resultant defect is usually repaired by a labial mucosal advancement flap. Vermilionectomy is performed under local anesthesia; the whole vermilion of the lower lip is resected, without touching the orbicularis muscle. Because the lip is a multilayered structure with important esthetic and functional roles, results have to be taken into consideration when planning reconstruction. The mucosa is advanced toward the skin to be sutured and thus close the defect. Some postoperative complications are hematoma, suture dehiscence and hypoesthesia [2]. One month after the vermilionectomy our patient didn't experienced those side effects.

Although a variety of different techniques have been described, reconstruction of defects resulting from vermilionectomy is classically performed with a mucosal advancement flap [10]. In this type of closure, the submucosa, which is undermined at the submucosal level until a sufficient amount of mucosa is prepared, will be advanced to close the defect, as it was realized in this case.

\section{Conclusion}

In terms of current treatment regimens, regardless of which therapy is chosen, aggres- 
sive treatment of AC is warranted to prevent invasive SCC from developing; a slip SCC has a high risk of metastasis. If the option is a conservative therapy, a standard clinic follow-up and new biopsies are strongly recommended after the treatment to evaluate the success of the technique. Finally, essential components of care include routine follow-up to monitor for disease recurrence and emphasis on ongoing sun protection habits.

\section{References}

[1] Barry, R.B.M., McKenzie, J., Berg, D. and Langtry, J.A.A. (2012) Direct Primary Closure without Undermining in the Repair of Vermilionectomy Defects of the Lower Lip. British Association of Dermatologists, 167, 1092-1097. http://dx.doi.org/10.1111/j.1365-2133.2012.11104.x

[2] Rossoe, E.W.T., Tebcherani, A.J., Sittart, J.A. and Pires, M.C. (2011) Actinic Cheilitis: Aesthetic and Functional Comparative Evaluation of Vermilionectomy Using the Classic and W-Plasty Techniques. Anais Brasileiros de Dermatologia, 86, 65-73. http://dx.doi.org/10.1590/S0365-05962011000100008

[3] Shah, A.Y., Doherty, S.D. and Rosen, T. (2010) Actinic Cheilitis: A Treatment Review. International Journal of Dermatology, 49, 1225-1234. http://dx.doi.org/10.1111/j.1365-4632.2010.04580.x

[4] Sarmento, D.J.S., Miguel, M.C.C., Queiroz, L.M.G., Godoy, G.P. and Silveira, E.J.D. (2014) Actinic Cheilitis: Clinicopathologic Profile and Association with Degree of Dysplasia. International Journal of Dermatology, 53, 466-472. http://dx.doi.org/10.1111/ijd.12332

[5] Narayanan, D.L., Saladi, R.N. and Fox, J.L. (2010) Ultraviolet Radiation and Skin Cancer. International Journal of Dermatology, 49, 978-986.

http://dx.doi.org/10.1111/j.1365-4632.2010.04474.x

[6] Ikehata, H. and Ono, T. (2011) The Mechanisms of UV Mutagenesis. Journal of Radiation Research, 52, 115-125. http://dx.doi.org/10.1269/jrr.10175

[7] Marrot, L. and Meunier, J.R. (2008) Skin DNA Photodamage and Its Biological Consequences. Journal of the American Academy of Dermatology, 58, 139-148. http://dx.doi.org/10.1016/j.jaad.2007.12.007

[8] Lucena, E.E.S., Costa, D.C.B., da Silveira, E.J.D. and Lima, K.C. (2012) Prevalence and Factors Associated to Actinic Cheilitis in Beach Workers. Oral Diseases, 18, 575-579. http://dx.doi.org/10.1111/j.1601-0825.2012.01910.x

[9] Lima, G.S., da Silva, G.F., Gomes, A.P.N., de Araújo, L.M.A. and Salum, F.G. (2010) Diclofenac in Hyaluronic Acid Gel: An Alternative Treatment for Actinic Cheilitis. Journal of Applied Oral Science, 18, 533-537. http://dx.doi.org/10.1590/S1678-77572010000500018

[10] Sand, M., Altmeyer, P. and Bechara, F.G. (2010) Mucosal Advancement Flap versus Primary Closure after Vermilionectomy of the Lower Lip. Dermatologic Surgery, 36, 1987-1992. http://dx.doi.org/10.1111/j.1524-4725.2010.01762.x 
Submit or recommend next manuscript to OALib Journal and we will provide best service for you:

- Publication frequency: Monthly

- 9 subject areas of science, technology and medicine

- Fair and rigorous peer-review system

- Fast publication process

- Article promotion in various social networking sites (LinkedIn, Facebook, Twitter, etc.)

- Maximum dissemination of your research work

Submit Your Paper Online: Click Here to Submit

Or Contact service@oalib.com 